\title{
Study of Structural and Morphological Properties of Vacuum Coated Copper (Cu) Metal Thin Film
}

\author{
M. M. Alam¹ ${ }^{*}$, Md. Nasrul Haque Mia², R. Hasan', M. Shahinuzzaman1, M. K. Islam¹, \\ Khan. M. Nasir Uddin ${ }^{1}$ \\ ${ }^{1}$ Department of Applied Physics, Electronics and Communication Engineering, Islamic University, \\ Kushtia, Bangladesh \\ ${ }^{2}$ Institute of Electronics, Atomic Energy Research Establishment Ganakbari, Savar, Dhaka, Bangladesh \\ Email: ${ }^{*}$ milon112000@gmail.com
}

Received 28 June 2015; accepted 7 August 2015; published 10 August 2015

Copyright (C) 2015 by authors and Scientific Research Publishing Inc.

This work is licensed under the Creative Commons Attribution International License (CC BY). http://creativecommons.org/licenses/by/4.0/

(c) (i) Open Access

\section{Abstract}

This study presented a technique to deposit high strength and highly conductive copper thin films on glass substrates at room temperature. In this work, $\mathrm{Cu}$ thin films with thicknesses $\sim 500 \mathbf{~ n m}$ have been deposited on glass substrate by thermal evaporation technique at room temperature. After deposition, these films have been annealed at $200^{\circ} \mathrm{C}$ for $10-40$ minutes. The thickness and annealing effect on the structural and morphological properties were studied by $\mathrm{X}$-ray diffraction (XRD) and scanning electron microscopy (SEM) respectively. The results showed that by increasing thickness the copper films crystallinity in (111) direction had been increased. Also by varying the annealing time the significant changes were observed in the films crystallinity and surface morphology.

\section{Keywords}

Thin Film, Crystallinity, Copper, Morphology

\section{Introduction}

In computer and microelectronics industry, copper plays an important role in the newest development of chip design. Aluminum are replacing by copper which is used to be the conductor of choice in transistor systems [1] [2]. Pure metals like copper, silver and aluminum are very soft. Strengthening these metallic films by various

\footnotetext{
*Corresponding author.
} 
approaches like grain size reduction, solid solution strengthening, cold working leads to high strengths but low electrical conductivity. For instance, Cu with 2 or 3 times, higher strength (achieved by alloying) usually has a loss of conductivity about 50 to 60 percent in comparison with pure copper. There are three different types coating processes: (1) vapor phase, which includes physical vapor deposition (PVD) and chemical vapor deposition (CVD); (2) liquid phase, which includes painting, dipping, and electroplating; and (3) solid phase, which includes plasma spray processes and laser cladding [3]. Depending on source of energy used for the deposition of coatings each process can again sub-classified. Among these methods electron beam physical vapor deposition (EBPVD) has the precise shape and high purity ability of controlling the deposition rate from $1 \mathrm{~nm}$ to several micrometers, which has been found in different applications in fabricating thermal barrier coatings, cutting tools, and electrical coatings. These coatings have been used when corrosion, oxidation and erosion are troublesome. Furthermore, PVD on a low substrate temperature increases the probability of forming nanocrystalline films [4]. The primary source of strengthening of thin films has been confining dislocation motion. Introduction of defects, such as grain boundaries and precipitates, has proven to be an effective technique to enhance mechanical strengths to a great extent. But these defects also act as a very powerful scattering site for electrons, and thus lead to a lower electrical conductivity. Such dilemma has led to exploration of a different type of defects, twin boundaries. Twin boundaries act as barriers to dislocation motion in a similar manner to grain boundaries, but the electrical scattering coefficient at coherent twin boundaries is about one order of magnitude lower than that at grain boundaries. Therefore there is great potential in design high-strength and high-conductivity $\mathrm{Cu}$ films by tailing twin boundaries. The primary goal of present work is to deposit copper, single crystal in nature with good balance of electrical and mechanical properties.

\section{Experimental Details}

Thermal evaporation technique has been used to deposit the Copper thin films on glass substrate. The glass substrate were used for copper thin film deposition and washed in a solution of 1/5/5 proportion of de-ionized water/oxygenated water/ammonia and dry in air. A Vecco EB-PVD apparatus was used at a rate of $0.1 \AA / \mathrm{sec}$ for copper deposition. Purity of copper stock was $4 \mathrm{~N}$ and substrate temperature was set at $70^{\circ} \mathrm{C}$ and $150^{\circ} \mathrm{C}$ for discrete runs. For comparison a 99.9\% copper foil was used. The base pressure of the thermal evaporation system was better at $1.6 \times 10^{-6}$ mbar. The samples were heated at $200^{\circ} \mathrm{C}$ for different time being. The film thickness was measured by using surface Profiler (Dektak-150) systems. The crystallographic structure of films was studied by X-ray diffraction (XRD) with $\mathrm{CoK}_{\alpha}(\lambda=0.179 \mathrm{~nm})$ using Philips X'pert PRO PW3040 instrument. The morphology of the samples was examined using Cam Scan mv2300 scanning electron microscope SEM.

\section{Results and Discussions}

\subsection{Thickness Measurement}

Copper thin films are deposited by thermal evaporation technique. After growth of thin films, they are annealed at $200^{\circ} \mathrm{C}$ for $10-40$ minutes and make three samples. During the thickness measurement process a surface profiler named Dektak-150 is used to measure a total $6400 \mu \mathrm{m}, 6800 \mu \mathrm{m}$ and $6500 \mu \mathrm{m}$ length of samle-1, sample-2 and sample-3 respectively.

Figure 1 shows the thickness of $\mathrm{Cu}$ thin film on glass substrate. The measurement resolution of sample- 1 , sample-2 and sample-3 are $0.427 \mu \mathrm{m} /$ sample, $0.453 \mu \mathrm{m} /$ sample and $0.433 \mu \mathrm{m} /$ sample respectively. During the process of measurements for all the samples, measurement duration was 50 seconds, stylus force was $3.00 \mathrm{mg}$ and stylus radius was $12.5 \mu \mathrm{m}$ and the measurement profile was Hills \& Valleys. As it is seen in the raw wafer of Figure 1, the surface profiles are almost smooth, flat but exists only a few measurement of fluctuations likely 50 angstrom to 100 angstrom which may be negligible. These fluctuations occurred may be due to the presence of dust particle.

\subsection{X-Ray Diffraction (XRD)}

Copper thin film was deposited onto glass substrate using thermal evaporation technique at deposition power of $1000 \mathrm{~W}$. After deposition, two samples were heated about $10 \mathrm{~min}, 20 \mathrm{~min}$ and $40 \mathrm{~min}$ at $200^{\circ} \mathrm{C}$ (Figures 2-4). $\mathrm{X}$-ray diffraction was done on all the samples to examine microstructures. Indexing is the process of determining the unit cell dimensions from the peak positions. It is the first step in diffraction pattern analysis. To index a 

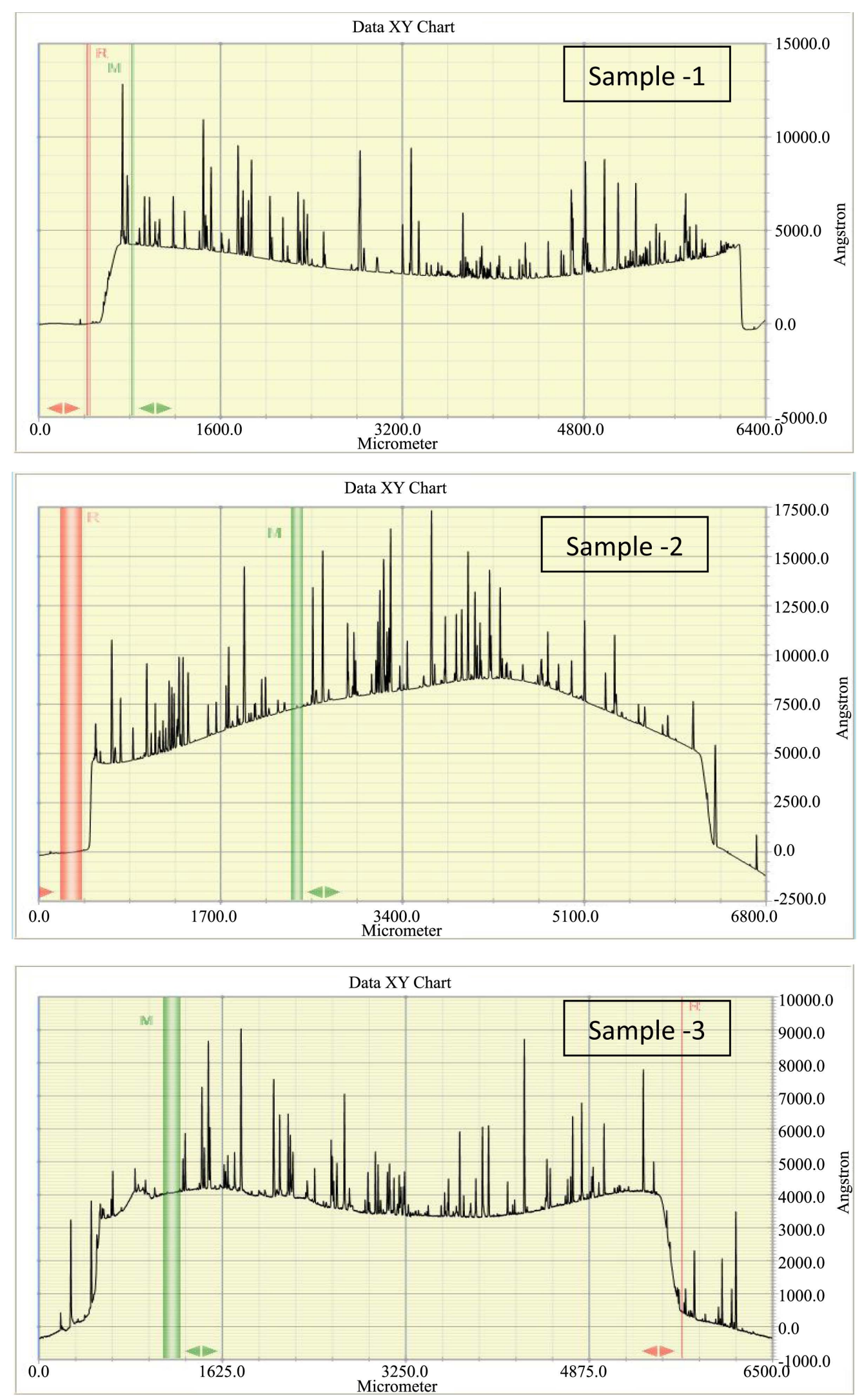

Figure 1. Thickness measurements of three samples by surface profiler (Dektak-150). 


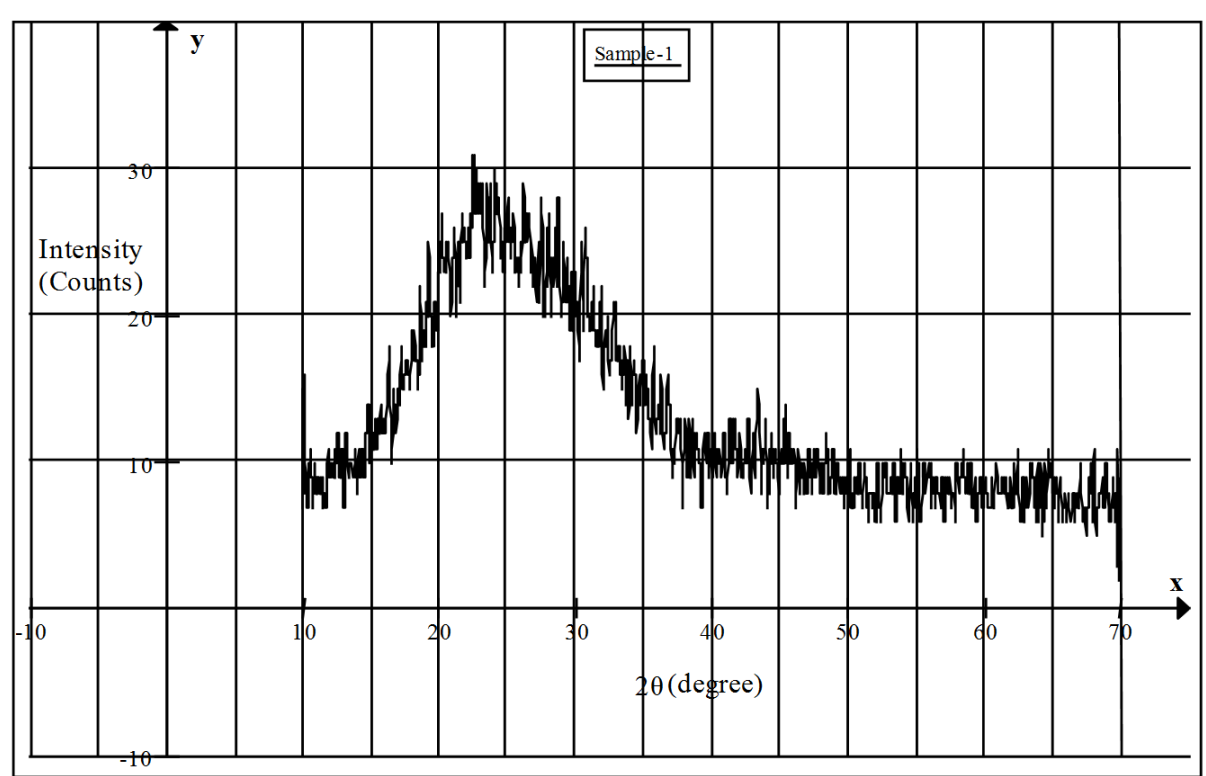

Figure 2. XRD spectra for $\mathrm{Cu}$ thin films on glass substrate annealed at $200^{\circ} \mathrm{C}$ for 10 minutes.

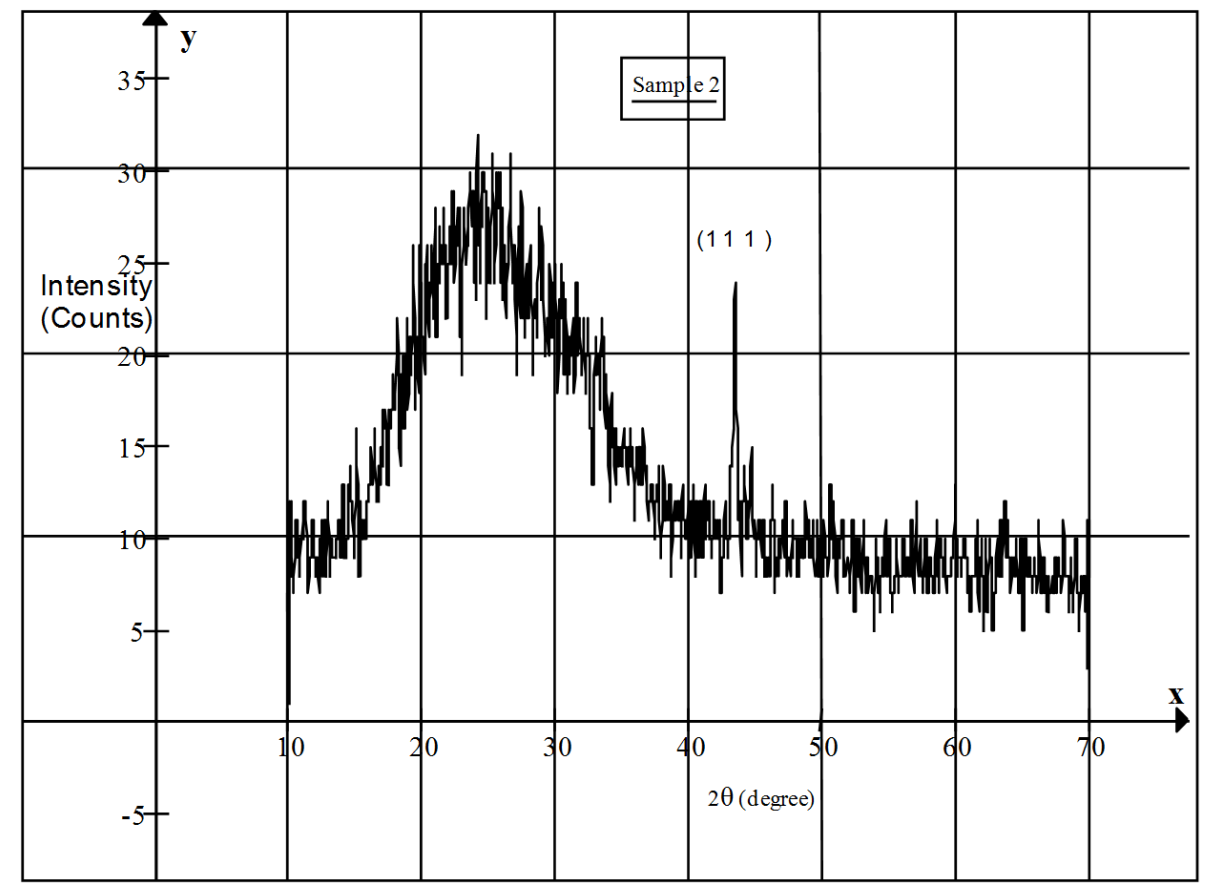

Figure 3. XRD spectra for $\mathrm{Cu}$ thin films on glass substrate annealed at $200^{\circ} \mathrm{C}$ for 20 minutes.

powder diffraction pattern it is necessary to assign Miller Indices (h k l) to each peak [5]. Unfortunately it is not just the simple reverse of calculating peak positions from the unit cell dimensions and wavelength.

\section{Calculation for XRD Data for Thin Film Annealed at $200^{\circ} \mathrm{C}$ for 40 Minutes}

XRD analysis of the prepared sample of copper thin film was done by a Goniometer (Ultima3 theta-theta gonio,

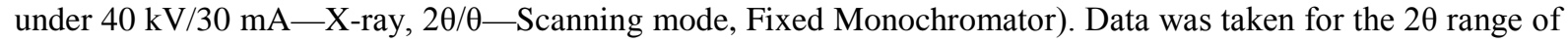
10 to 70 degrees with a step of 0.02 degree. Data for some $2 \theta$ range has given in Table 1 . Indexing process of powder diffraction pattern was done and Miller Indices ( $\mathrm{k} \mathrm{l}$ ) to each peak was assigned in first step. Diffractogram of the entire data is in Figure 4. 


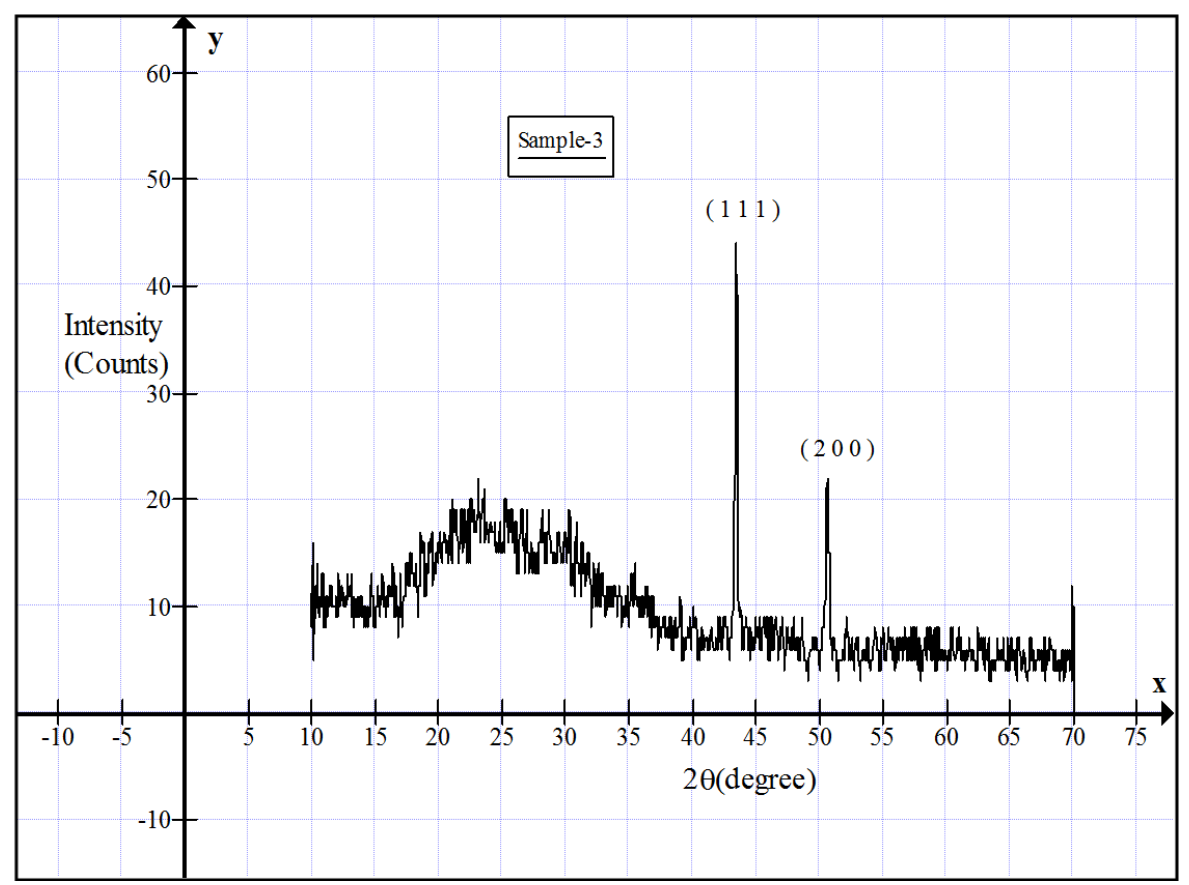

Figure 4. XRD spectra for $\mathrm{Cu}$ thin films on glass substrate annealed at $200^{\circ} \mathrm{C}$ for 40 minutes.

Table 1. Simple peak indexing.

\begin{tabular}{ccccc}
\hline Peak position, $2 \theta$ & $1000 \times \operatorname{Sin}^{2} \theta$ & $1000 \times \operatorname{Sin}^{2} \theta / 46$ & Reflection & Remarks \\
\hline 43.4630 & 137 & 3 & $\left(\begin{array}{lll}1 & 1\end{array}\right)$ & $1^{2}+1^{2}+1^{2}=3$ \\
50.6161 & 183 & 4 & $(200)$ & $2^{2}+0^{2}+0^{2}=4$ \\
\hline
\end{tabular}

Indexing has been done in two different methods and data are in Table 1 \& Table 2 . In Table 1 , one need to find a dividing constant and the values in the 3rd column becomes integers (approximately). Here, the constant is 46 (=183 - 137). Moreover, the high intense peak for FCC materials is generally (1 11 1) reflection, which is observed in the sample [6]. Two peaks at $2 \theta$ values of 43.4630 and 50.6161 degree corresponding to (1 11 ) and (2 00 ) planes of copper are observed and compared with the standard powder diffraction card of JCPDS, copper file No. 04-0836 [7].

Table 3 shows the experimentally obtained X-ray diffraction angle and the standard diffraction angle of Cu specimen. The XRD study confirms/indicates that the resultant particles are (FCC) copper thin film. It has been investigated that the samples have crystalline structure with the preferred orientation direction in (1 111$)$ plane which is the highest peak in the XRD pattern [8]. The XRD studies have also shown the dependence of the crystal structure to changing temperature. It is observed that the increase in the X-ray diffraction pattern is more visible in the temperatures. Therefore, it results in an increase in temperature and growing in the grain sizes in the structure of the films, which is also the reason of increasing intensity of diffraction peaks.

\subsection{Scanning Electron Microscopy (SEM) Study}

The morphology of the surface and cross-section of relatively pure copper films was examined by scanning electron microscopy. We observed three thin films and for each film SEM images were taken with three different magnitudes like 3000x, 15,000xs and 30,000xs. Figure 5-7 shows the SEM images of deposited copper film by the thermal evaporation technique annealed at $200^{\circ} \mathrm{C}$ for different time durations (10 - 40 minutes).

The microstructure of the films was substantially affected by the annealing temperature. When the film was annealed at $200^{\circ} \mathrm{C}$, the morphology did not change much but showed better uniformity in grain size. The grains had a homogeneous distribution on the surface, however, there were some new and bigger features shown 


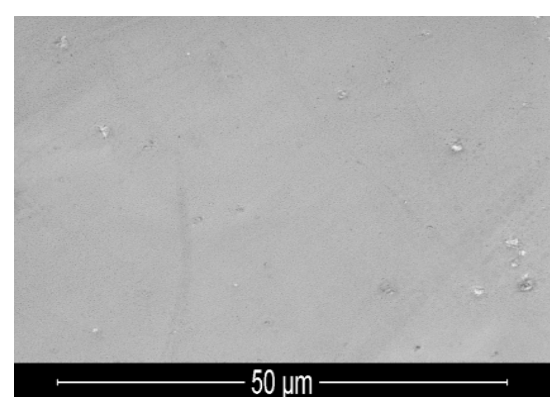

(a)

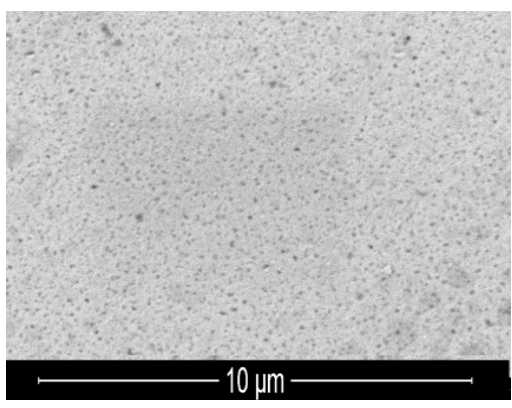

(b)

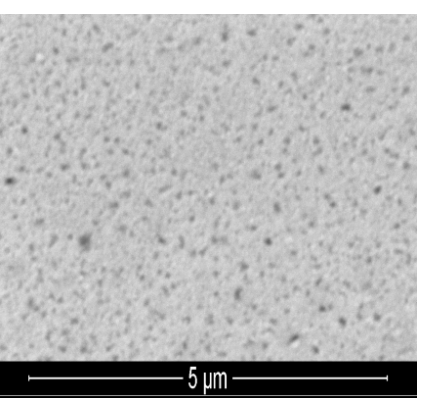

(c)

Figure 5. SEM images of $\mathrm{Cu}$ thin film on glass substrate annealed at $200^{\circ} \mathrm{C}$ for 10 minutes.

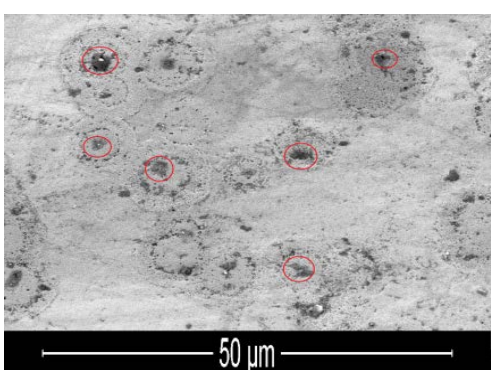

(a)

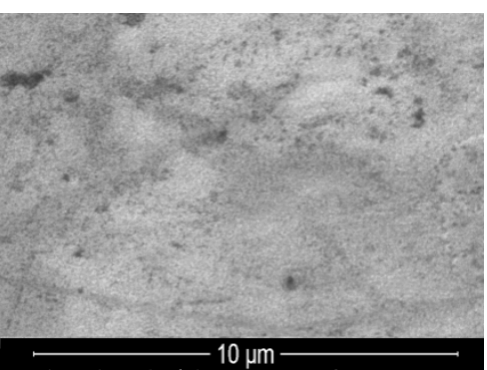

(b)

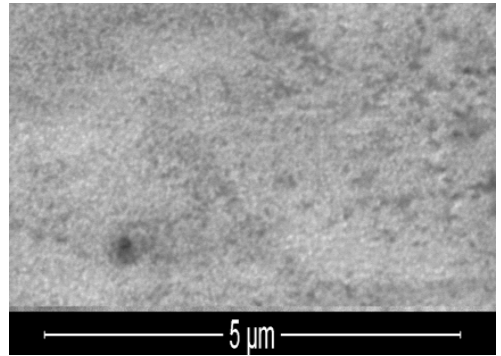

(c)

Figure 6. SEM images of $\mathrm{Cu}$ thin film on glass substrate annealed at $200^{\circ} \mathrm{C}$ for 20 minutes.

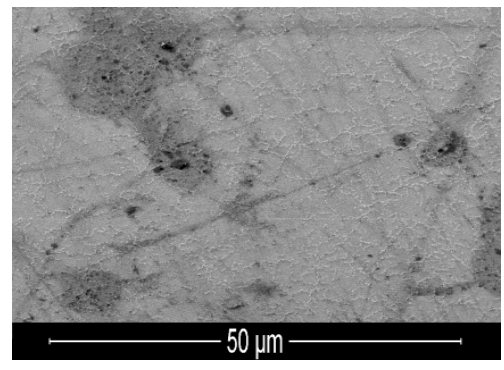

(a)

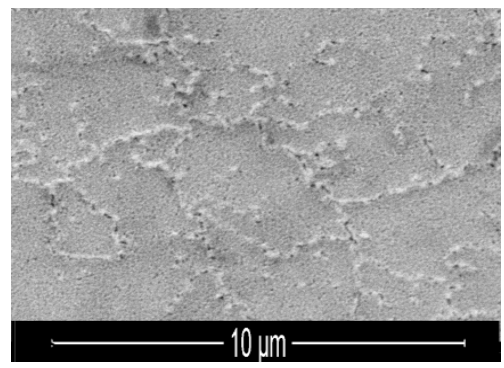

(b)

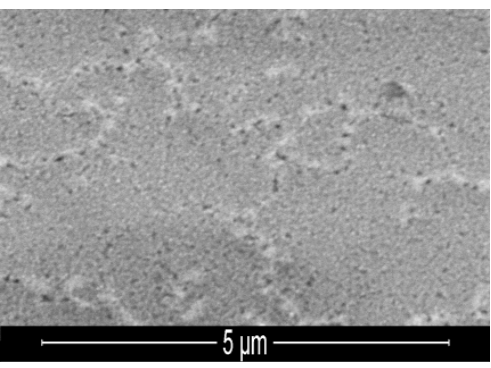

(c)

Figure 7. SEM images of $\mathrm{Cu}$ thin film on glass substrate annealed at $200^{\circ} \mathrm{C}$ for 40 minutes.

Table 2. Peak indexing from d-spacing.

\begin{tabular}{ccccc}
\hline $2 \theta$ & $\mathrm{D}$ & $1000 / \mathrm{d}^{2}$ & $\left(1000 / \mathrm{d}^{2}\right) / 77.33$ & $\mathrm{hkl}$ \\
\hline 43.4630 & 2.08216 & 230.65 & 2.98 & $(111)$ \\
50.6161 & 1.80193 & 307.98 & 3.98 & $(200)$
\end{tabular}

Table 3. Experimental and standard diffraction angles of $\mathrm{Cu}$ specimen.

\begin{tabular}{|c|c|}
\hline $\begin{array}{l}\text { Experimental diffraction angle } \\
\text { ( } 2 \theta \text { in degrees) }\end{array}$ & $\begin{array}{l}\text { Standard diffraction angle ( } 2 \theta \text { in degrees) } \\
\text { JCPDS copper: } 04-0836\end{array}$ \\
\hline 43.463 & 43.297 \\
\hline 50.616 & 50.433 \\
\hline
\end{tabular}

by red circle which was shown in Figure 6(a). The SEM image for copper thin film annealed at $200^{\circ} \mathrm{C}$ for 40 minutes showed no visible defects on the film as shown in Figure 7. 


\section{Conclusion}

Copper thin films were deposited by thermal evaporation method on glass substrate and its structural and morphological analysis had been investigated. The films were annealed at $200^{\circ} \mathrm{C}$ for different time XRD analysis, it had been investigated that the samples had crystalline structure with the preferred orientation direction in $\left(\begin{array}{lll}1 & 1 & 1\end{array}\right)$ plane increases with the annealing time. Heat treatments of the copper layers after deposition were another ways to increase the grain size of the small grains created by evaporation. The temperature during deposition was identified as the biggest influence on the microstructure of the evaporated material and in the current setup the substrate temperature was completely unknown. This study had revealed that copper thin film deposition via thermal evaporation was a cheap and fast method.

\section{References}

[1] Arnaud, L., Tartavel, G., Berger, T., Mariolle, D., Gobil, Y. and Touet, I. (2000) Microstructure and Electromigration in Copper Damascene Lines. Microelectronics Reliability, 40, 77-86. http://dx.doi.org/10.1016/S0026-2714(99)00209-7

[2] Koetter, T.G., Wendrock, H., Schuehrer, H., Wenzel, C. and Wetzig, K. (2000) Relationship between Microstructure and Electromigration Damage in Unpassivated PVD Copper Damascene Interconnects. Microelectronics Reliability, 40, 1295-1299. http://dx.doi.org/10.1016/S0026-2714(00)00140-2

[3] Singh, J. and Wolfe, D.E. (2005) Review Nano and Macro-Structured Component Fabrication by Electron BeamPhysical Vapor Deposition (EB-PVD). Journal of Materials Science, 40, 1-26.

http://dx.doi.org/10.1007/s10853-005-5682-5

[4] Ustinov, A.I., Movachan, B.A. and Polishchuk, S.S. (2004) Formation of Nanoquasicrystalline Al-Cu-Fe Coatings at Electron Beam Physical Vapour Deposition. Scripta Materialia, 50, 533-537. http://dx.doi.org/10.1016/j.scriptamat.2003.10.025

[5] Cullity, B.D. and Stock, S.R. (2001) Elements of X-Ray Diffraction. 3rd Edition, Prentice-Hall, Englewood Cliffs, 169.

[6] Yeganeh, M. and Saremi, M. (2011) Deposition of Thin Film Copper Nanostructures by Electron Beam Physical Vapor Deposition Technique on $\mathrm{SIO}_{2} / \mathrm{p}$-Type $\mathrm{Si}(100)$ and Study of Its Oxidation Behavior. International Journal of Modern Physics B, 25, 2567-2574. http://dx.doi.org/10.1142/S0217979211101867

[7] Jiang, H., Klemmer, T.J., Barnard, J.A., Doyle, W.D. and Payzant, E.A. (1997) Epitaxial Growth of Cu(111) Films on Si(110) by Magnetron Sputtering: Orientation and Twin Growth. Thin Solid Films, 315, 13-16. http://dx.doi.org/10.1016/S0040-6090(97)00954-1

[8] Smith, D. (1995) Thin Film Deposition: Principles and Practice. McGraw-Hill, Inc., New York. 